\title{
Power Consumption Modeling based on Real-Time Data Traffic for Balancing Power Supply and Energy Demand to Develop Green Telecommunication Tower: A Case Study
}

\author{
Ahmed Abdulmula \\ Solar Energy Research Institute \\ National University of Malaysia \\ Bangi, Malaysia \\ abdulmula@yahoo.com
}

\author{
Kamaruzzaman Sopian \\ Solar Energy Research Institute \\ National University of Malaysia \\ Bangi, Malaysia \\ kospian@ukm.edu.my
}

\author{
Lim Chin Haw \\ Solar Energy Research Institute \\ National University of Malaysia \\ Bangi, Malaysia \\ chinhaw.lim@ukm.edu.my
}

\begin{abstract}
Green telecommunication tower primarily depends on renewable energy and energy efficiency technologies. This study presents a power consumption model to estimate the load demand of a telecommunication tower (TT) to improve energy efficiency. The method is based on field measurements of realtime data traffic load of the entire operated macrocell telecommunication tower to balance power supply and energy demand. This advanced method is investigated using HOMER Pro simulation and compared with a widely accepted technique called overall peak load method for a chosen case study. The comparison simulation results showed that by using the power consumption model method, the energy-saving efficiency at the TT is improved by $24.19 \%$ and the size of the overall system is decreased by $33.33 \%$. Consequently, the annualized cost is reduced by $25.7 \%$. This optimum performance contributes to the effective development of green telecommunication towers.
\end{abstract}

Keywords-green telecommunication tower; solar energy technology; energy consumption modeling; data traffic load

\section{INTRODUCTION}

The diversity of services provided by the mobile telecommunications industry has led to a significant increase in the capacity of data traffic and has thus increased energy consumption and $\mathrm{CO}_{2}$ emission [1]. Increasing the number of subscribers leads to a significant increase in data traffic transfer [2]. TTs serve as terminal links between the subscribers and the data center, so cellular network operators (CNOs) constantly need building TTs to increase coverage areas and data transfer capacity for improving the quality of services. Three significant problems are considered by CNOs when building TTs. At first, the locations are carefully selected without any coverage holes or unnecessary overlap. Then, given that TTs consume around $60 \%$ of the total cost of network operating expenditures, increasing the cost of running the network, it is necessary to reduce energy consumption as much as possible. Also, the provision of electricity to TTs in off-grid sites is an issue. In the past, in off-grid sites, diesel generators (DGs) were widely used for powering TTs. However, they have become less favorable because of their close relation to increased operating and maintenance costs and harmful effects on the environment [37]. The challenge for $\mathrm{CNO}$ is to provide the reliable power required to run TTs in an off-grid site where the electrical energy is unavailable without resorting to costly and environmentally unfriendly power systems. Renewable energy sources of enormous potential availability have been developed and used globally to reduce the economic cost and the impact to the environment [8-13]. The recent enhancements in solar energy technology solutions have made adopting advanced green technology of an off-grid solar power generation for energy-efficient TT the optimal viable solution to attain green TTs. Such concept reliably generates power without interruption, thereby eliminating dependence on DGs. This advanced green technology can reduce carbon emissions and operating expenses [14]. Regarding the use of green technology, its energy efficiency must be improved because the sizing of green power generation for TTs depends not only on geo-location and weather [15], but also on the dynamics of energy consumption of TT. Therefore, the load demand must be accurately estimated to sustain a balance between electricity supply and energy demand. Based on that, appropriately sizing an off-grid solar power generation system requires accurate knowledge of the TT electricity demand including calculating total daily energy consumption and the peak load.

This study aims to develop the concept of an off-grid green solar power system for macrocell TT by proposing an efficient method of estimating the TT load profile with high accuracy. The method is based on modeling the power consumption through actual real-time data traffic measurements that reflect the interdependence between energy consumption of TT and its data traffic load. The critical contribution of this study is the proposal of a powerful energy management technology method for shifting the energy efficiency of TTs in the off-grid site by ensuring the balance between supply power and energy demand. The benefit of applying this method is energy-saving efficiency, i.e. avoiding extra costs due to increased power consumption. The technique also minimizes the sizing of 
power system generation and thus reduces the initial cost with optimized performance. To demonstrate the benefits of the proposed method, techno-economic analysis comparison is conducted using HOMER Pro for the proposed power consumption model and overall peak load method for a chosen case study of the power generation system. The effect of the two qualified methods on sizing responses, initial cost, cash flow, and energy cost produced by the power system is investigated. To the best of the authors' knowledge, this comparison has never been performed before.

\section{LITERATURE REVIEW}

Various previous studies on the sizing of off-grid power systems for TTs have been conducted to increase costeffectiveness and reliability. In [5,16-19], authors used the overall peak load method to estimate the hourly load profile of TTs, which depends on the determined peak load. However, the hourly load profile changes depending on the hourly data traffic load of the radio equipment. The reason is that a close interconnection exists between the data traffic transfer capacity of the radio equipment and its power consumption. In other words, the power consumption of any TT depends on the hourly data traffic load, which is affected by the activeness of subscribers in the use of smartphones during night and day [2024]. Also, the sizing of power generation systems depends on the hourly load profile needs of the TT. Accordingly, the specific estimated load demand is significant for designing green power systems of energy-saving efficiency and optimized performance.

\section{RESEARCH METHODOLOGY}

\section{A. Energy Consumption Modeling}

TTs consume the highest proportion of energy among other units of the cellular network [2]. To balance power supply and energy consumption of TT, the energy consumption of TT per hour of the day and every day of the year must be determined. Moreover, knowledge about the energy consumption of the radio equipment of TT and the effect of the capacity of data traffic load on the hourly power consumption are needed. Regarding power consumption, the radio equipment of macrocell TT consists of two component types, loadindependent and load-dependent components. Loadindependent components include the microwave link, rectifier, and air conditioner. The power consumption of these components are constant and not affected by the capacity of data transfer. Load-dependent components include the transceiver, digital signal processing, and power amplifier. The power consumption of these components strongly varies depending on the data traffic transfer. The hourly energy consumption of the TT is estimated by the sum of the energy consumption of these components. With the variation in the activity of subscribers in the use of smartphones, the capacity of data traffic load by TT varies continuously. It gradually increases during the day when subscribers are active and then progressively decreases during the night until the early hours of the morning when most subscribers are asleep, and the data traffic is lower. TT energy consumption is directly proportional to the capacity of data traffic load, which increases in the day and decreases at night. Thus, the overall peak load must be considered in power consumption modeling for balancing power supply and energy demand. The power consumption in Watt (W) of a macrocell TT can be determined by (1):

$$
P_{T T}(W)=P_{\text {ind }}(W)+\sum_{i} P_{d p}(W) \times F_{i}
$$

where $P_{\text {ind }}$ is the sum of power consumption for the components that have load independent (const) (W), $P_{d p}$ is the power consumption of the components that have load dependent (depend on data traffic load) (W), $F_{i}$ is a load factor which reflects the efficiency of electrical energy usage, equal to the average load divided in peak load, $\left(i=0 \ldots . .0 \leq F_{i} \geq 1\right)$. The values of $F i$ are determined through actual measurements.

$$
\begin{aligned}
& P_{\text {ind }}(W)=\eta_{-} s \times P_{-} r(W)+P_{-} L(W)+P_{-} \text {air }(W) \text { (2) } \\
& P_{d p}(W)=\mathrm{\eta}_{s}\left[\eta_{T x}\left(P_{\text {amp }}(W)+P_{\text {trns }}(W)\right)+P_{\text {pro }}(W)\right](3)
\end{aligned}
$$

where $\eta_{s}$ is the number of sectors, $\eta_{T X}$ is the number of transmitting antennas per sector, $P_{r}$ is the power consumption of rectifier $(\mathrm{W}), P_{L}$ is the power consumption of microwave link (W), $P_{\text {air }}$ is the power consumption of air condition (W), $P_{\text {amp }}$ is the power consumption of power amplifier (W), $P_{t r n s}$ is the power consumption of the transceiver (W), $P_{\text {pro }}$ is the power consumption of digital signal processing in (W).

The power consumption of load-independent components and some parameters of long-term evolution (LTE) macrocell TT for the considered technologies are summarized in Table I [25]. The power consumption of the power amplifier, digital signal processing, and transceiver (load-dependent components) vary during the time depending on the change in the capacity of data traffic load of the TT.

\section{1) Measurement Setup}

To determine the power consumption of the TT, actual realtime data traffic measurements were performed at an operating LTE macrocell TT in Bangi, Selangor, Malaysia (Figure 1). The TT is owned by Celcom Bhd, which is the oldest and one of the largest CNOs in Malaysia with coverage of over $99 \%$ throughout Malaysia and over 12 million mobile subscribers. The TT components were fed with a constant DC voltage of approximately $54 \mathrm{~V}$. Using (4), the power consumption in Watt in a specific time was determined by actual real-time measurements of the current $I$ in ampere (A) at any time. The current $I$ was measured using the PEL 103 data logger and E3N current clamp over three consecutive months. Figure 2 shows a photograph of the measurement setup.

$$
P(t)=V \times I(t)
$$

\section{2) Measurements and Modeling Results}

From the actual measurements shown in Figure 3 and after the value of 1.25 was added as a safety factor, the hourly power consumption for three months was collected, averaged, and modeled. The result of the average full-day power consumption is plotted in Figure 4. The results illustrate that energy consumption continually changes: it increases during the day and gradually decreases at night. This result is due to the disparity in the rate of the use of smartphones by subscribers between day and night. This condition confirms the existence of a close relationship between the TT energy consumption and the capacity rate of data traffic transfer. When the capacity of 
data traffic increases, the power consumption of the TT also increases, and vice versa. The minimum power consumed is $1.0 \mathrm{KW}$ at 6:00 AM, whereas the maximum power consumed is $1.233 \mathrm{KW}$ at 7:00 PM. The average total daily energy consumption is $27.29 \mathrm{KWh} /$ day. The considered estimation load demand model completely improves the TT efficiency and guarantees the balance between power supply and energy demand without any shortage or waste of electricity.

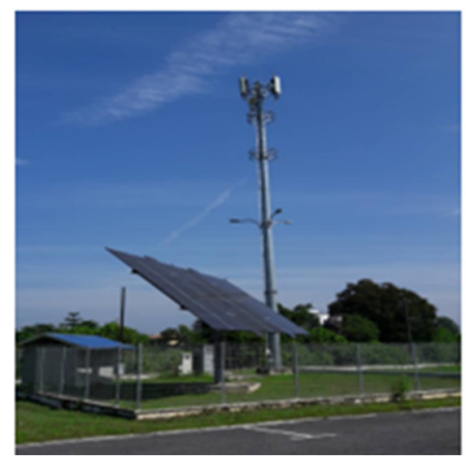

Fig. 1. Photograph of the macrocell TT

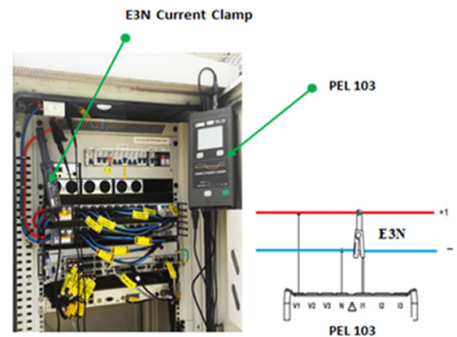

Fig. 2. Measurement setup

TABLE I. POWER CONSUMPTION OF LOAD-INDEPENDENT COMPONENTS AND CHARACTERISTICS FOR LTE MACROCELL TT

\begin{tabular}{|c|c|}
\hline Components and parameters & Value \\
\hline Rectifier $P_{r}$ & $100 \mathrm{~W}$ \\
\hline Microwave link $P_{L}$ & $80 \mathrm{~W}$ \\
\hline Air condition $P_{\text {air }}$ & $\begin{array}{c}\text { Not including (passive } \\
\text { ventilation) }\end{array}$ \\
\hline Number of sectors $\eta_{s}$ & 3 \\
\hline Number of transmitting antennas per sector $\eta_{T x}$ & 1 \\
\hline
\end{tabular}

\section{B. A Case Study Description and HOMER Pro Simulation}

Full autonomy stand-alone high-efficiency heterojunction intrinsic thin (HIT) film solar modules coupled with state-ofthe-art dual-axis maximum light detection (MLD) solar tracking system with a battery bank were established using the HOMER Pro software as a case study. Additional details of the system are available in [26, 27]. It is a most advanced green technological power system that has been designed in Malaysia through collaboration among Solar Energy Research Institute (SERI), Universiti Kebangsaan Malaysia (UKM), and Celcom Bhd mobile telecommunication company in Green Innovation Park, UKM, Bangi. Figure 5 shows the TT load profile of the case study that was estimated by the overall peak load estimation method based on the peak load of $1.5 \mathrm{~kW}$. The system involves the following components: (i) HIT Panasonic photovoltaic cells made of mono-crystalline and amorphous silicon layers. (ii) Dual-axis tracking system with MLD controller. (iii) Twenty-four units of battery bank of CL 2000, valve-regulated lead acid (VRLA) battery storage system with a capacity of $2,000 \mathrm{Ah} / 2 \mathrm{~V}$ for each battery. (iv) Three units of solar controllers with maximum power point tracking (MPPT) of $48 \mathrm{~V} / 64 \mathrm{~A}$.

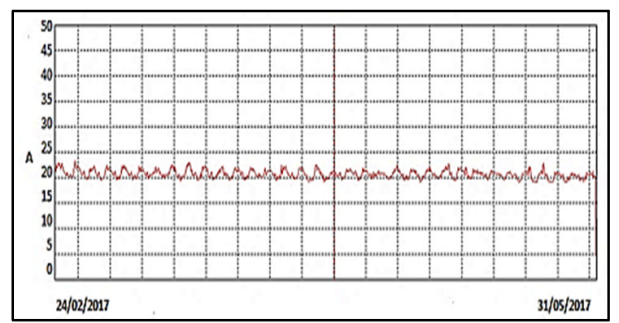

Fig. 3. Screenshot of observation logging for three months of a change in amperage under real-time data traffic load

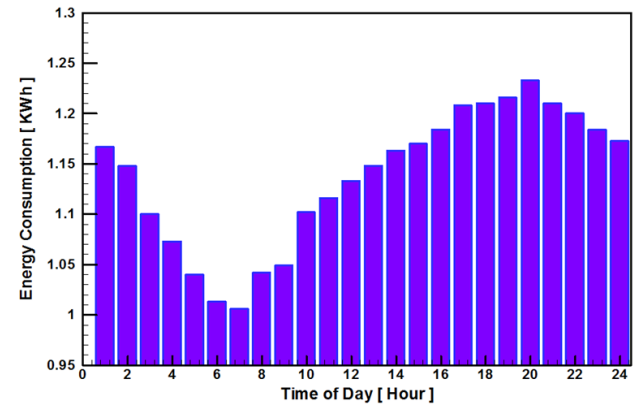

Fig. 4. A 24-hour TT energy consumption based on real-time data traffic

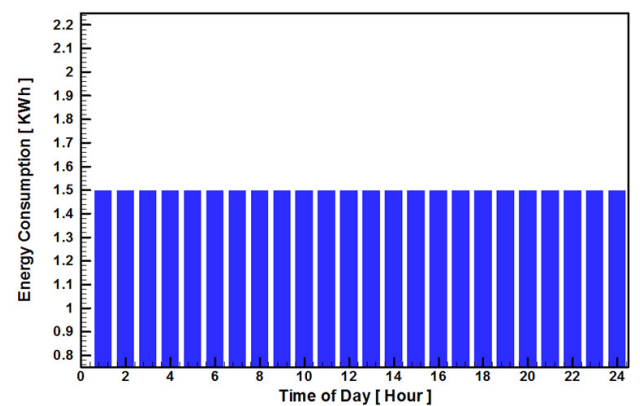

Fig. 5. Load profile estimation of TT based on overall peak load estimation method

A techno-economic analysis was performed using HOMER Pro to compare the two methods and determine their effect on the power generation system (our case study). HOMER Pro is powerful in simulation and optimization, and has been used in many studies. The software displays all simulation and optimization results in charts and tables for comparison and evaluation in technical and economic terms [28-31]. HOMER Pro determines the optimal power system depending on various values of TT load profile, technical and economic parameters of components, and solar radiation and temperature of the site. The estimated specific load profile of TT, the conventional overall peak load estimation method and the proposed power consumption model based on real-time data traffic were used. 
Figures 6, 7 show the results of the load profile calculation of both methods. The values represent the electric load needed by the TT each hour of the day throughout the year. The total daily energy consumption and the peak load for the power consumption model based on real-time data traffic (first method) and the overall peak load estimation method (second method) are $27.29 \mathrm{KWh} /$ day and $1.233 \mathrm{KW}$ and $36 \mathrm{KWh}$ /day and $1.5 \mathrm{KW}$ respectively. The data of solar radiation and temperature of the site were downloaded from the National Renewable Energy Lab Database and NASA Surface Meteorology and Solar Energy database (Table II). The details of the technical and financial parameters for the HOMER simulation setup are shown in Table III.

TABLE II. MONTHLY AVERAGE OF HORIZONTAL IRRADIANCE, CLEARNESS INDEX, AND TEMPERATURE OF THE SITE

\begin{tabular}{|c|c|c|c|}
\hline Month & $\begin{array}{c}\text { Daily radiation } \\
\left(\mathbf{K W h} / \mathbf{m}^{\mathbf{2}} \mathbf{d a y}\right)\end{array}$ & $\begin{array}{c}\text { Clearness } \\
\text { index }\end{array}$ & $\begin{array}{c}\text { Daily } \\
\text { temperature }\left({ }^{\mathbf{}} \mathbf{C}\right)\end{array}$ \\
\hline January & 5.332 & 0.546 & 25.360 \\
\hline February & 6.003 & 0.590 & 25.900 \\
\hline March & 5.878 & 0.562 & 26.090 \\
\hline April & 5.664 & 0.548 & 26.108 \\
\hline May & 5.182 & 0.523 & 26.240 \\
\hline June & 5.274 & 0.549 & 25.860 \\
\hline July & 5.223 & 0.538 & 25.500 \\
\hline August & 5.350 & 0.530 & 25.650 \\
\hline September & 5.403 & 0.522 & 25.730 \\
\hline October & 5.455 & 0.535 & 25.910 \\
\hline November & 5.109 & 0.521 & 25.760 \\
\hline December & 5.215 & 0.546 & 25.360 \\
\hline
\end{tabular}

TABLE III. TECHNICAL AND FINANCIAL COMPONENT PARAMETERS

\begin{tabular}{|c|c|c|}
\hline Components & Parameters & Value \\
\hline \multirow{10}{*}{ SPV } & Installation type & $\begin{array}{l}\text { Dual-axis solar tracking system } \\
\text { with maximum light detection } \\
\text { (MLD) controller. }\end{array}$ \\
\hline & Module size & $240 \mathrm{~W}$ \\
\hline & Sizes considered $(\mathrm{KW})$ & $\begin{array}{c}3,4,5,6,7,8,9,10,11,12,13 \\
14,15\end{array}$ \\
\hline & Efficiency & $95 \%$ \\
\hline & Derating factor & $93 \%$ \\
\hline & Lifetime & 25 years \\
\hline & Ground reflectance & $25 \%$ \\
\hline & Initial capital cost & $\$ 2000 / \mathrm{KW}$ \\
\hline & Replacement cost & $\$ 1000 / \mathrm{KW}$ \\
\hline & Operation \& maintenance & $\$ 25$ per year \\
\hline \multirow{3}{*}{ MPPT } & Initial capital cost & $\$ 250 / \mathrm{KW}$ \\
\hline & Replacement cost & $1,2,3,4,5,6,7 \mathrm{KW}$ \\
\hline & Considered lifetime & 15 years \\
\hline \multirow{7}{*}{ Battery bank } & Number of batteries & 24 \\
\hline & Nominal voltage & $2 \mathrm{~V}$ \\
\hline & Nominal capacity & $2000 \mathrm{Ah}$ \\
\hline & Initial capital cost & $\$ 300$ \\
\hline & Replacement cost & $\$ 300$ \\
\hline & Maintenance cost & Free \\
\hline & Lifetime & 5 years \\
\hline
\end{tabular}

\section{RESULTS AND DISCUSSION}

After entering all required input data, the HOMER Pro 3.8.3 software was run for the case study, firstly using the power consumption model based on real-time data (first method), then using the overall peak load estimation (second method). The HOMER Pro searched to obtain the best optimal sizing in order to cover all power needs at the lowest of the total present cost (NPC) of each system component including costs in $\$$ of capital, replacement, operation, and maintenance throughout the life of the project. Also, the minimum of the levelized cost of energy (LCOE) and characteristic of annual energy production was obtained.

\section{A. Estimated Optimal Sizing (First Method)}

Figure 6 shows the schematic of the modeled system. The estimated total daily energy consumption and peak load for load profile are $27.29 \mathrm{KWh} /$ day and $1.233 \mathrm{KW}$, respectively. The technical and financial parameters of the system components and the solar and temperature site resources are the same as presented in Tables II and III. The obtained results of the HOMER Pro optimization sizing of the system, showed in Figure 7, comprise $8 \mathrm{KWp}$ of the solar PV array, 24 units of CL 2000, VRLA, AGM battery bank, and 4KW of MPPT. The levelized cost of energy (LCOE) of the system and the total NPC were $0.229 \$ / K W h$ and $\$ 29,524.46$ respectively. Figure 8 shows the NPC summary of components. The graphics represent the NPC costs for the dual-axis PV solar tracking system, MPPT, battery bank respectively, and the total value of the system which are respectively $\$ 16,025.86, \$ 1,344.46$, $\$ 12,154.19$, and $\$ 29,524.46$.

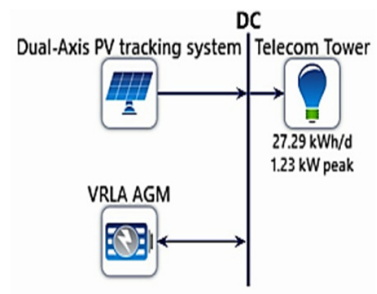

Fig. 6. System architecture of the adaptive first method

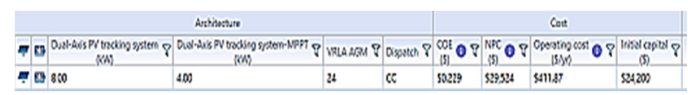

Fig. 7. Screenshot of HOMER optimization result of using the first method

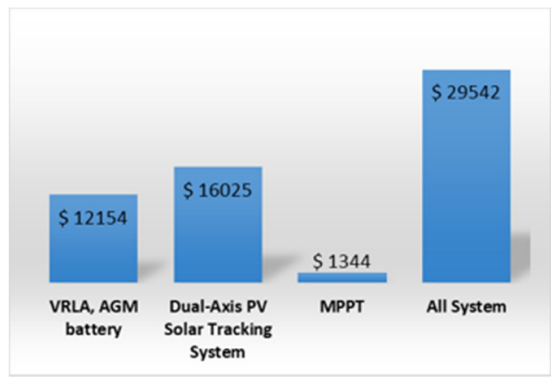

Fig. 8. Summary of NPC of the system components using the first method

The result of optimization indicated that the annual output of energy production was $12,897 \mathrm{KWh} / \mathrm{yr}$ with $4 \mathrm{KW}$ of MPPT. This value is higher than the yearly load consumption of $9,960.85 \mathrm{KWh} / \mathrm{yr}$. The variables indicate that the amount of energy produced by solar PV panels covers all energy consumed with a slight increase of $18.3 \%$, which can be 
considered a safety factor. This result is due to the balance between the production and consumption of power. Thus, the system works very efficiently without any shortage or high increase in capacity.

\section{B. Estimated Optimal Sizing (Second Method)}

Figure 9 depicts the power system architecture using the second method. The total daily energy consumption and peak load of the macrocell TT by using this method are $36 \mathrm{KWh} /$ day and $1.5 \mathrm{KW}$ respectively. Figure 10 shows the result of the optimization system configuration suggested by HOMER Pro, that was $12 \mathrm{KWp}$ of the solar PV array, 24 units of CL 2000, VRLA, AGM battery bank, and 6KW of MPPT. By using this method, the size of components increases compared to the first method, which also increases the cost of the overall system. Consequently, the optimization results of total NPC and LCEO of the system are $\$ 39,730.36$ and $0.234 \$ / \mathrm{KWh}$, respectively. Figure 11 illustrates the NPC values of components for the second method. The costs for the dual-axis PV solar tracking system, MPPT, and battery bank are $\$ 24,039, \$ 2,017$, and $\$ 13,675$, respectively.

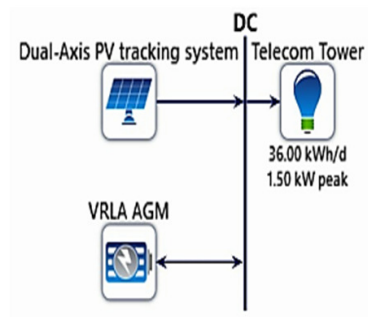

Fig. 9. Power system architecture using the second method

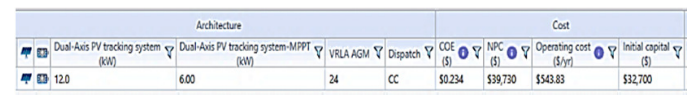

Fig. 10. Screenshot of the optimization result of the system configuration using the second method

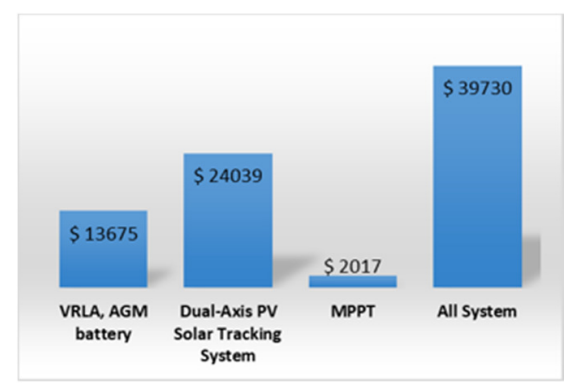

Fig. 11. Summary of NPC of the system components using the second method

By using the overall peak load estimation method, the annual output of energy production was $19,345 \mathrm{KWh} / \mathrm{yr}$. This amount of energy is considerably more than the estimated consumption need of $13,131 \mathrm{KWh} / \mathrm{yr}$. Thus, the excess electricity is $5,449 \mathrm{KWh} / \mathrm{yr}$, equal to $28.2 \%$ of the total annual energy production. This value is high and thereby causing a waste of energy and higher cost.

\section{Comparison of the Two Methods}

The graph in Figure 12 shows the comparison result of the total NPC between the two methods. By using the first method, the saving values of NPC for the dual-axis solar tracking system, battery bank, and MPPT are \$8,012.9 (33.33\%), $\$ 1,520.81 \quad(11.12 \%)$, and $\$ 672.3 \quad(33.33 \%)$ respectively compared with the second method. Thus, the saving value of NPC for the entire system is $\$ 10,206(25.68 \%)$. Table IV presents the results of the variation in SPV sizing, LCOE, and annualized costs of both methods. Using the power consumption model based on real-time data traffic (first method), the SPV sizing, MPPT sizing, LCOE, and annualized cost decrease by $33.33 \%, 33.33 \%, 2.13 \%$, and $25.7 \%$, respectively compared with the second method. Thus, the proposed method makes a realistic estimation of the load profile because of its size efficiency and reduces economic cost during the lifetime of the project.

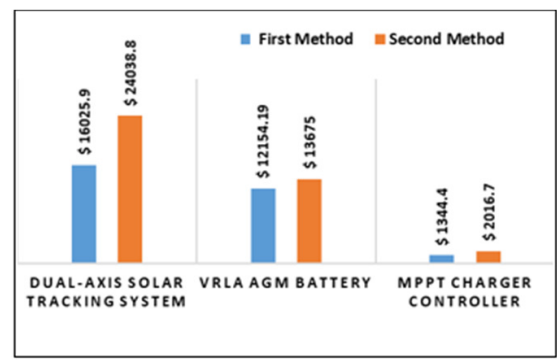

Fig. 12. Comparative result of the NPC summary of both methods

TABLE IV. DETAILED COMPARATIVE ANALYSIS RESULTS

\begin{tabular}{|c|c|c|c|c|}
\hline Description & First method & $\begin{array}{c}\text { Second } \\
\text { method }\end{array}$ & Savings & Decrease \% \\
\hline $\begin{array}{c}\text { Load profile } \\
\text { estimited }\end{array}$ & $27.29 \mathrm{Kwh} / \mathrm{d}$ & $36 \mathrm{KWh} / \mathrm{d}$ & $8.71 \mathrm{KWh} / \mathrm{d}$ & 24.19 \\
\hline $\begin{array}{c}\text { SPV component } \\
\text { size }\end{array}$ & $8 \mathrm{KWp}$ & $12 \mathrm{KWp}$ & $4 \mathrm{KWp}$ & 33.33 \\
\hline MPPT size & $4 \mathrm{KW}$ & $6 \mathrm{KW}$ & $2 \mathrm{KW}$ & 33.33 \\
\hline Annualized cost & $\$ 2,284$ & $\$ 3,073$ & $\$ 789$ & 25.7 \\
\hline $\begin{array}{c}\text { Levelized cost of } \\
\text { energy }\end{array}$ & $\$ 0.229 / \mathrm{KWh}$ & $\$ 0.234 / \mathrm{KWh}$ & $\$ 0.005 / \mathrm{KWh}$ & 2.13 \\
\hline
\end{tabular}

Moreover, the first method obtained an energy-saving efficiency of up to $8.71 \mathrm{KWh} /$ day, and significantly improves the efficiency of TT by up to $24.19 \%$ compared with the second method. This improvement in energy efficiency is due to the fact that the first method depends on the balance between power supply and energy demand, which causes no waste of energy, while the second method is based on supplying electricity equal to the peak load all the time.

\section{CONCLUSION}

Green TTs in off-grid sites evolved rapidly over the past decade because of their utilization of advanced technologies of solar power and energy-efficiency solutions. This study proposed a critical method to estimate the TT's load profile to develop the concept of green macrocell TT. The proposed power consumption method, based on real-time data traffic, achieves balance between power supply and energy consumption needs. The optimization findings confirm that the 
proposed method has energy-saving efficiency and avoids extra costs caused by excessive power supply. Additionally, it minimizes the size of the system, which reduces the space required to install PV arrays. As a result, the total cost during the lifetime of the project is lower. For these reasons, adapting the proposed method contributes to the improvement of energy efficiency and hence, effective development of green telecommunication towers.

\section{ACKNOWLEDGEMENT}

The authors acknowledge the financial contribution of this study through the assistance of a grant from the Economic Transformation Program (ETP-2013-020).

\section{REFERENCES}

[1] M. Meo, E. Le Rouzic, R. Cuevas, C. Guerrero, "Research challenges on energy-efficient networking design", Computer Communications, Vol. 50, pp. 187-195, 2014

[2] J. Wu, Y. Zhang, M. Zukerman, E. K. N. Yung, "Energy-efficient basestations sleep-mode techniques in green cellular networks: A survey", IEEE Communications Surveys \& Tutorials, Vol. 17, No. 2, pp. 803826,2015

[3] C. Han, T. Harrold, S. Armour, I. Krikidis, S. Videv, P. M. Grant, H. Haas, J. S. Thompson, I. Ku, C. X. Wang, T. A. Le, M. R. Nakhai, J. Zhang, L. Hanzo, "Green Radio: Radio Techniques to Enable EnergyEfficient Wireless Networks", IEEE Communications Magazine, Vol. 49, No. 6, pp. 46-54, 2011

[4] K. Kusakana, H. J. Vermaak, "Hybrid renewable power systems for mobile telephony base stations in developing countries", Renewable Energy, Vol. 51, pp. 419-425, 2013

[5] M. H. Alsharif, R. Nordin, M. Ismail, "Energy optimization of a hybrid off-grid system for remote telecommunication base station deployment in Malaysia", EURASIP Journal on Wireless Communications and Networking, Vol. 2015, 2015

[6] G. K. Singh, "Solar power generation by PV (photovoltaic) technology: A review”, Energy, Vol. 53, pp. 1-13, 2013

[7] D. Yamegueu, Y. Azoumah, X. Py, N. Zongo, "Experimental study of electricity generation by Solar PV/diesel hybrid systems without battery storage for off-grid areas", Renewable Energy, Vol. 36, pp. 1780-1787, 2011

[8] E. A. Al-Ammar, "Application of Using Hybrid Renewable Energy in Saudi Arabia”, Engineering, Technology \& Applied Science Research, Vol. 1, No. 4, pp. 84-89, 2011

[9] J. B. V. Subrahmanyam, P. Alluvada, Bandana, K. Bhanupriya, C. Shashidhar, "Renewable Energy Systems: Development and Perspectives of a Hybrid Solar-Wind System", Engineering, Technology \& Applied Science Research, Vol. 2, No. 1, pp. 177-181, 2012

[10] J. Barzola, M. Espinoza, F. Cabrera, "Analysis of Hybrid Solar/Wind/Diesel Renewable Energy System for off-grid Rural Electrification", International Journal of Renewable Energy Research, Vol. 6, No. 3, pp. 1146-1152, 2016

[11] R. Bingham, M. Agelin-Chaab, M. Rosen, "Feasibility of a Hybrid Solar and Wind Power System for an Island Community in the Bahamas", International Journal of Renewable Energy Research, Vol. 6, No. 3, pp. 951-963, 2016

[12] H. S. Das, A. Dey, C.W. Tan, A. H. M. Yatim, "Feasibility Analysis of Standalone PV/Wind/Battery Hybrid Energy System for Rural Bangladesh", International Journal of Renewable Energy Research, Vol. 6, No. 2, pp. 402-412, 2016

[13] A. Zubair, A. Tanvir, M. Hasan, "Optimal Planning of Stand Alone Solar-Wind-Diesel Hybrid Energy System for a Coastal Area in Bangladesh", International Journal of Electrical and Computer Engineering, Vol. 2, No. 6, pp. 731-738, 2012

[14] A. M. Aris, B. Shabani, "Sustainable power supply solutions for off-grid base stations", Energies, Vol. 8, pp. 10904-10941, 2015
[15] E. Banguero, H. David, A. Arias, A. Julian, A. Cardona, "Renewable microgrid operational results and economic evaluation using RETScreen TM", International Journal of Electrical and Computer Engineering, Vol. 9, No. 2, pp. 723-731, 2019

[16] M. El Badawe, T. Iqbal, G. K. Mann, "Optimization and a Comparison between Renewable and Non- Renewable Energy System for Telecommunication Site", 25th IEEE Canadian Conference on Electrical and Computer Engineering, Montreal, Canada, April29-May 2, 2012

[17] M. H. Alsharif, R. Nordin, M. Ismail, "Green Wireless network optimization strategies within smart grid environments for Long Term Evolution (LTE) cellular networks in Malaysia", Renewable Energy, Vol. 85, pp. 157-170, 2016

[18] R. M. Asif, "Cellular Base Station Powered by Hybrid Energy Options", International Journal of Computer Applications, Vol. 115, No. 22, pp. 35-39, 2015

[19] A. Sharma, A. Singh, M. Khemariya, "Homer Optimization Based Solar PV; Wind Energy and Diesel Generator Based Hybrid", International Journal of Soft Computing and Engineering, Vol. 3, No. 1, pp. 199-204, 2013

[20] O. Arnold, F. Richter, G. Fettweis, O. Blume, "Power Consumption Modelling of Different Base Station Types in Heterogeneous Cellular Networks", 2010 Future Network \& Mobile Summit, Florence, Italy, June 16-18, 2010

[21] L. A. Case, S. K. Khadka, J. N. Shrestha, S. R. Shakya, "A Regression Analysis for Base Station Power Consumption under Real Traffic Loads- A Case of Nepal", American Journal of Engineering Research, Vol. 4, No. 12, pp. 85-90, 2015

[22] M. Deruyck, W. Joseph, L. Martens, "Power consumption model for macrocell and microcell base stations", Transactions on Emerging Telecommunications Technologies, Vol. 25, No. 3, pp. 320-333, 2014

[23] J. D. Gadze, S. B. Aboagye, K. A. Agyekum, "Real-Time Traffic Bas Station Power Consumption Model for Telecom in Ghana", International Journal of Computer Science and Telecommunications, Vol. 7, No. 5, pp. 6-13, 2016

[24] J. Lorincz, T. Garma, G. Petrovic, "Measurements and modeling of base station power consumption under real traffic loads", Sensors, Vol. 12, No. 4, pp. 4181-310, 2012

[25] M. Deruyck, E. Tanghe, W. Joseph, W. Vereecken, M. Pickavet, L. Martens, B. Dhoedt, "Model for the power consumption of wireless access networks", IET Science, Measurement and Technology, Vol. 5, No. 4, pp. 155-161, 2011

[26] A. Abdulmula, K. Sopian, L. C. Haw, A. Fazlizan, "Performance evaluation of standalone double axis solar tracking system with maximum light detection MLD for telecommunication towers in Malaysia", International Journal of Power Electronics and Drive Systems, Vol. 10, No. 1, pp. 444-453, 2019

[27] A. Fudholi, L. C. Haw, K. Sopian, A. Mohamed, O. Abdulmula, "A Primary Study of Tracking Photovoltaic System for Mobile Station in Malaysia", International Journal of Power Electronics and Drive Systems, Vol. 9, No. 1, pp. 427-432, 2018

[28] S. Bahramara, M. P. Moghaddam, M. R. Haghifam, "Optimal planning of hybrid renewable energy systems using HOMER: A review", Renewable and Sustainable Energy Reviews, Vol. 62, pp. 609-620, 2016

[29] D. K. Lal, B. B Dash, A. K. Akella, "Optimization of PV/Wind/MicroHydro/Diesel Hybrid Power System in HOMER for the Study Area", International Journal on Electrical Engineering and Informatics, Vol. 3, No. 3, pp. 307-325, 2011

[30] J. B. Fulzele, S. Dutt, "Optimum Planning of Hybrid Renewable Energy System Using HOMER", International Journal of Electrical and Computer Engineering, Vol. 2, No. 1, pp. 68-74, 2012

[31] F. Chermat, M. Khemliche, A. Badoud, S. Latreche, "Techno-Economic Feasibility Study of Investigation of Renewable Energy System for Rural Electrification in southern Algeria”, Engineering, Technology \& Applied Science Research, Vol. 8, No. 5, pp. 3421-3426, 2018 